\title{
REACTION OF FINANCIAL ANALYSTS \\ TO MANAGEMENT EARNINGS FORECASTS
}

\author{
By \\ Robert H. Jennings \\ Indiana University
}

Monograph 20 


\section{REACTION OF FINANCIAL ANALYSTS \\ TO MANAGEMENT \\ EARNINGS FORECASTS}

\section{ERRATA TO PAGE 6}

Institutional Brokers Estimate System (I/B/E/S), a service of Lynch, Jones \& Ryan, is available on a weekly basis. This weekly availability extends from well before the initial study date and continues, uninterrupted, through today. The database will continue to be updated daily and the summary statistics recomputed and made available to clien ts weekly.

In the study period, $\mathrm{I} / \mathrm{B} / \mathrm{E} / \mathrm{S}$ reported on 2,400 companies. The data were collected from 65 major brokerage firms. Today, data is available on over 3,200 companies with contributed forecasts from over 100 brokerage firms and over 25 institutions. 
Copyright ${ }^{\oplus} 1985$

by

The Financial Analysts Research Foundation

Charlottesville, Virginia

All Rights Reserved

\title{
Financial Analysts Research Foundation Monograph Series
}

\author{
Richard F. DeMong, CFA \\ Research Director
}

No. 17 Edmund A. Mennis, CFA Understanding Corporate Penand Chester D. Clark, FSA sion Plans, 1983

No. 18 Robert W. Kolb and Gerald D. Gay

No. 19 James E. Hatch and Robert W. White

No. 20 Robert H. Jennings
Interest Rate and Stock Index Futures and Options: Characteristics, valuation and Portfolio Strategies, 1985

Canadian Stocks, Bonds, Bills and Inflation: $1950-1983$, 1985

Reaction of Financial A nalysts to Management Earnings Forecasts, 1985 
I would like to thank Leonard Zacks of Zacks Investment Research, Inc. for providing the financial analyst forecast data used in this study. 


\section{CONTENTS}

I INTRODUCTION 1

II THE DATA AND METHODOLOGY

A. Data 5

$\begin{array}{ll}\text { B. Methodology } & 7\end{array}$

III ANALYST RESPONSE TO MANAGEMENT EARNINGS FORECASTS $\quad 12$

IV THE OPTIMALITY OF ANALYST RESPONSE 23

$\begin{array}{ll}\text { V SUMMARY } & 29\end{array}$

$\begin{array}{ll}\text { APPENDIX } & 32\end{array}$

FOOTNOTES 34

REFERENCES 37 


\section{THE FINANCIAL ANALYSTS RESEARCH FOUNDATION}

\section{Board of Trustees and Officers}

Alfred C. Morley, CFA, President

The Institute of Chartered

Financial Analysts

P.O. Box 3668

Charlottesville, Virginia 22903

James R. Vertin, CFA, Vice President

Alpine Counselors

136 Pecora Way

Menlo Park, California 94025

George W. Noyes, CFA, Secretary

Standish, Ayer \& Wood, Inc.

1 Beacon Street

Boston, Massachusetts 02116

Edus H. Warren, Jr., CFA, Treasurer

Capital Research Company

280 Park Avenue

New York, New York 10017

Richard F. DeMong, CFA, Research Director

McIntire School of Commerce

Monroe Hall-University of Virginia

Charlottesville, Virginia 22903

John C. Burton

Columbia University

101 Uris Hall

New York, New York 10027

Charles A. D'A mbrosio, CFA, Ex Officio

University of Washington

Graduate School of Business

Administration

Seattle, Washington 98195

M. H. Earp, CFA

Brittany Associates, Inc.

P. O. Box 26177

Dallas, Texas 75226

Charles D. Ellis, CFA

Greenwich Research Associates

Office Park Eight

Greenwich, Con necticut 06830

William S. Gray, III, CFA

Harris Trust \& Savings Bank

111 West Monroe Street

Chicago, Illinois 60690

Jay O. Light

Harvard Business School

Baker 331

Boston, Massachusetts 02163

Edmund A. Mennis, CFA

Consultant to Investment Management

405 Via Chico, Suite 7

Palos Verdes Estates,

California 90274
Robert D. Milne, CFA

Duff \& Phelps Investment

Managemenı Co.

710 Ohio Savings Plaza

Cleveland, Ohio 44114

Roger F. Murray

P.O. Box 669

Wolfeboro, New Hampshire 03894

Matthias Plum, Jr.

Global Investments, L.P.

600 Atlantic Avenue, Suite 1400

Boston, Massachusetts 02110

William G. Shenkir, Ex Officio McIntire School of Commerce University of Virginia, Monroe Hall Charlottesville, Virginia 22903

A. A. Sommer, Jr.

Morgan, Lewis \& Bockius $1800 \mathrm{M}$ Street, N. W.

Washington, D. C. 20036

Walter P. Stern, CFA

Capital Research Company

280 Park Avenue

New York, New York 10017

Jack L. Treynor

Treynor-Arbit Associates

111 West Jackson Boulevard

Chicago, Illino is 60604

Donald L. Tuttle, CFA

Indiana University

Graduate School of Business

Bloomington, Illinois 47405

Jay Vawter, CFA, Ex Officio

Stein Roe \& Farnham

1271 Avenue of the Americas

New York, New York 10020

Chairman, Institute of Chartered

Financial Analysis

Ernest R. Widmann, CFA, Ex Officio

Widmann, Blee \& Co. Incorporated

One Station Circle

Narbeth, Pennsylvania 19072

Chairman, Financial Analysts

Federation

Arthur Zeikel

Merrill Lynch Asset

Management, Inc.

633 Third Avenue

New York, New York 10017 


\section{THE FINANCIAL ANALYSTS RESEARCH FOUNDATION AND ITS PUBLICATIONS}

1. The Financial Analysts Research Foundation is an autonomous charitable foundation, as defined by Section 501 (c) (3) of the Internal Revenue Code. The Foundation seeks to improve the professional performance of financial analysts by fostering education, by stimulating the development of financial analysis through high quality research, and by facilitating the dissemination of such research to users and to the public. More specifically, the purposes and obligations of the Foundation are to commission basic studies (1) with respect to investment securities analysis, investment management, financial analysis, securities markets and closely related areas that are not presently or adequately covered by the available literature, (2) that are directed toward the practical needs of the financial analyst and the portfolio manager, and ( 3 ) that are of some enduring value. The Financial Analysts Research Foundation is affiliated with The Financial Analysts Federation, The Institute of Chartered Financial Analysts, and the University of Virginia through The McIntire School of Commerce.

2. Several types of studies and publications are au thorized:

A. Studies based on existing knowledge or methodology which result in a different arrangement of the subject. Included in this category are papers that seek to broaden the understanding within the profession of financial analysis through reviewing, distilling, or synthesizing previously published theoretical research, empirical findings, and specialized literature;

B. Studies that apply known techniques, methodology, and quantitative methods to problems of financial analysis;

C. Studies that develop new approaches or new solutions to important problems existing in financial analysis;

D. Pioneering and original research that discloses new theories, new relationships, or new knowledge that confirms, rejects, or extends existing theories and concepts in financial analysis. Ordinarily, such research is intended to improve the state of the art. The research findings may be supported by the collection or manipulation of empirical or descriptive data from primary sources, such as original records, field interviews, or surveys.

3. The views expressed in this book and in the other studies published by the Foundation are those of the authors and do not necessarily represent the official position of the Foundation, its Board of Trustees, or its staff. As a matter of policy, the Foundation has no official position with respect to specific practices in financial analysis.

4. The Foundation is indebted to the voluntary financial support of its institutional and individual sponsors by which this and other publications are made possible. As a 501 (c) (3) foundation, contributions are welcomed from interested donors, including individuals, business organizations, institutions, estates, foundations, and others. Inquiries may be directed to:

Research Director

The Financial Analysts Research Foundation

University of Virginia, Post Office Box 3665

Charlottesville, Virginia 22903

(804) 924-3051 


\section{INTRODUCTION}

Perhaps the best evidence of the economic importance of earnings per share forecast data is the quantity of resources devoted to the production and analysis of such information by the investment community. Investors appear to impute special importance to information relevant to future earnings figures. Givoly and Lakonishok (1983, p.1), for example, state that: "Earnings per share emerge from various studies as the single most important accounting variable in the eyes of the investors." Likewise, investment firms seem eager to provide the data. In addition to the earnings forecasts provided by nearly every full-service brokerage house, at least three sources exist (Standard and Poors' Earnings Forecaster, Lynch, Jones and Ryan's Institutional Brokerage Estimation System and the Icarus Service of Zacks Investment Research, Inc.) which aggregate many brokers' beliefs and provide investors with consensus earnings forecasts.

Academic research over the last decade or so also provides substantial support for the usefulness of such earnings information. Gonedes, Dopuch and Penman (1976) rank firms based on forecasted earnings/price (E/P) ratios and form four portfolios based on thoses $E / P$ rankings. They find that, on average, the highest $\mathrm{E} / \mathrm{P}$ portfolio earns risk-adjusted returns significantly greater than expected while the returns on the lowest $\mathrm{E} / \mathrm{P}$ firms are less than expected.

Although Gonedes, Dopuch and Penman document return predictive ability from the (normalized) absolute level of forecast earnings, most research concentrates on forecast errors (forecasted EPS minus actual EPS) or revisions in forecasts. Neiderhoffer and Regan (1972) find that high (low) equity returns were associated with firms, in which analysts underestimated (overestimated) earnings relative to actual. Thus, those investors able to produce consistently more accurate earnings estimates would be capable of producing consistently greater portfolio returns. Zacks (1979) and Elton, Gruber and Gultekin (1981) provide evidence that knowledge of the consensus analyst earnings forecast itself is of no value. However, both studies show that the ability to anticipate movements in the consensus forecast or to foresee the forecast error would be extremely valuable to investors. Givoly and Lakonishok (1979) and (1980) further document the association between revisions in analyst forecasts and stock price movements. 
While the link between the revisions of analyst earnings forecasts and subsequent stock price movements is well supported by the extant empirical evidence, little research effort has been exerted attempting to identify the factors that are important to financial analysts in forming their earnings per share forecasts. This study examines the response of financial analysts' forecasts to one potential source of information: earnings forecasts attributed to the firm's management.

Although the exact model used to construct an earnings per share forecast is difficult to specify precisely, typically it is posited that information concerning the general economy, the economic sector/industry and the specific firm are somehow combined to produce the desired result. It is likely that the weights attached to each of these three types of information vary depending on who is preparing the EPS forecast. Specifically, it is possible that firm management has superior firm-specific data and, therefore, places special significance on this when estimating earnings. Analysts, on the other hand, may rely more heavily on macro-economic and industry data. If this firm-specific data is useful to firm management in their forecasts of earnings, it seems reasonable to assume financial analysts (FA) also would find the information valuable and would incorporate that data in to their forecasts at the point in time it becomes available to them. Thus, to the extent that the manager's announcement at least partially reveals the manager's inside information, one would expect a response in the earnings forecasts of financial analysts.

The first part of this study, therefore, examines the behavior of consensus financial analyst EPS forecasts around the dates on which management forecasts are made public. Specifically, this investigation seeks to determine whether the FA appears to find the public announcement of a management forecast a relevant event when preparing his or her own earnings estimate. A more complete knowledge of the type of data useful to an analyst in forecasting EPS will lead to a better understanding of how such forecasts are constructed. This understanding may, in turn, provide investors and researchers valuable insights in to the security return generating process.

Besides the rather vague benefit of a better understanding of the financial analyst belief formation process, this study should provide more direct payoffs. One question concerns the issue of information efficiency. If the market is perfectly information efficient, the public announcement of the manager's EPS forecast should provide little new data for the analyst. From independent data collection efforts 
the FA should have been able to uncover the information on which the manager bases his or her forecast. In this case, one would expect to find that changes in the FA forecast anticipate the public announcement of the management forecast. If, on the other hand, the market is not perfectly information efficient, the manager indeed may have information that cannot be discovered by the financial analyst from external sources.

Another motive for studying the reaction of analyst forecasts to the release of a management forecast is to evaluate the usefulness of managers' forecasts to investors. In the 1970s the Securities and Exchange Commission debated the imposition of mandatory management EPS forecasts. To the extent that financial analysts are representative of the general investing community, ${ }^{1}$ a finding that $\mathrm{FA}$ forecasts respond to the release of management estimates would be consistent with the claim that managers possess information that might remain undisclosed to investors without the announcement of an EPS forecast. On the other hand, if management forecasts are based on the same data set used by investors-resulting in minimum FA forecast revision upon the release of management forecast-the rationale for requiring the management forecast is weakened considerably.

The above discussion is concerned with whether the financial analyst responds to a management earnings forecast and the timing of that reaction relative to the release of the manager's estimate. If it is determined that analysts do react to the information contained in the management forecast, another issue is the analysts' ability to use that information optimally. In this context the term optimally denotes a situation in which the analyst is able to combine the information contained in the manager's forecast with his or her prior data to form superior (more accurate) forecasts. This implies that the FA must be able to correctly discount the management forecast when the prior FA forecast is more accurate than management's prediction and correctly react to the management forecast in those cases in which management is more accurate. In other words, the financial analyst should not merely mimic the manager.

The justification for this is that, since the production and dissemination of a financial analyst's forecast consume resources, the financial analyst must "add value." In this context, value is added by using the management announcement to produce superior forecasts. Consider the belief formation model suggested previously. Ostensibly, management possesses superior firm-specific data. Analysts, on the other hand, may possess superior industry 
and/or general economic information due to their more objective viewpoint or their familiarity with the competitive relationship of the firms in an industry. The release of the manager's EPS estimate should provide the analyst with insights into the managers' firm-specific data. The analyst, in turn, should be able to use this insight to produce superior forecasts. If the FA forecast only mimics the management number, the SEC conceivably could conserve societal resources by mandating management forecasts, thereby eliminating (or at least reducing) the need for analyst forecasts.

The remainder of this paper consists of four sections. The following section discusses the data sources and methodology used in the analysis. In the third section I present the results of tests designed to determine if analysts respond to the release of management EPS forecasts. The question of whether analysts make optimal use of the management estimate is addressed in the fourth section. The paper concludes with a summary of the findings and some suggestions for further research. 


\section{THE DATA AND METHODOLOGY}

In the first part of this section, the forecast data base used in this study is described. The latter part of this portion of the paper details the empirical techniques employed to address the issues under study.

\section{A. Data}

In order to assess the issue of financial analyst response to management earnings forecasts, a sample of forecast data was constructed. Since management forecasts are issued relatively infrequently, the first portion of the data set consisted of management earnings forecasts. The data set was completed by gathering financial analyst earnings forecasts of those firms for which management forecasts were obtained.

The Dow Jones News Retrieval Service (DJNRS) was used as the source of management earnings forecasts. The DJNRS contains a data base of articles published by Dow Jones \& Company in The Wall Street fournal and Barrons as well as any announcements appearing on the Broad Tape but not published. This computerized data base is constantly updated and can be accessed on an on-line basis. The data base is accessed by specifying certain keywords that relate to the topic of interest. A text search procedure is used to scan either headlines or entire articles for the selected keywords. Any headline or article containing the keywords can be retrieved for examination.

The keywords used to query the data base were words that would indicate the article was reporting a management forecast of EPS. In response to inquiries using these keywords, approximately 2,150 articles published between June 1979 and December 1982 were retrieved. Each article was examined to determine if it contained a useful annual EPS forecast. To be included in the sample, the following conditions were imposed:

1. The forecast was attributed to a corporate official;

2. The forecast was a specific point estimate of annual EPS or, if range estimates were presented, the midpoint was used;

3. The forecast had to be issued at least one month before year-end; and, 
4. In order for more than one forecast for a given firm/fiscal year to be used the two forecasts had to be more than twenty weeks apart. ${ }^{2}$ For any pair of forecasts not meeting this five-month screen, only the forecast occurring earlier in the fiscal year was retained.

Upon imposing these constraints, a sample of 191 usable management forecasts of annual EPS was obtained for this study. ${ }^{3}$

After this management forecast sample was assembled, weekly consensus analyst forecasts of EPS were collected. The source of the analyst forecasts was Zacks Investment Company's Icarus Service. Zacks accumulates up to sixty analyst forecasts for about 2,400 companies and resells them to interested subscribers. Beginning with its inception in November of 1979, the service has reported, among other things, a weekly consensus analyst annual EPS forecast and the number of analysts included in the consensus computation.

The Zacks data base is superior to other available data sources due to the frequency of its updating and its extensive coverage of analysts. The Standard and Poor's Earnings Forecaster is published weekly but generally follows considerably fewer analysts. On the other hand, IBES from Lynch, Jones and Ryan offers extensive analyst coverage but is only updated monthly which is too infrequent to be very useful in the type of analysis performed in this study. Thus, the Zacks' data base offers a unique combination of attributes in dealing with consensus date.

Consensus analyst forecasts were collected, both before and after the date of the management forecasts, for a maximum of twenty weeks in either direction. The data collection can be best understood by envisioning a time line (Figure 1). The week of a management forecast is defined as time 0 . Weeks after the management forecast week are numbered +1 to +20 . Weeks before the management forecasts are numbered -1 to -20 . The weeks directly preceding and after the management forecast are designated -1 and +1 , respectively.

As far as was possible consensus analyst forecasts were obtained for each firm with a management forecast for weeks -20 through $+20 .{ }^{4}$ After examining the data base provided by Zacks for analyst forecasts of the firms that had management forecasts, 115 firms (principally traded over the counter) were found that were missing or had incomplete data. Therefore, the sample for this study consists of seventy-six management forecasts. (See the Appendix for a list of the firms used in the study.) 
Weeks before the management forecast
Weeks after the management forecast

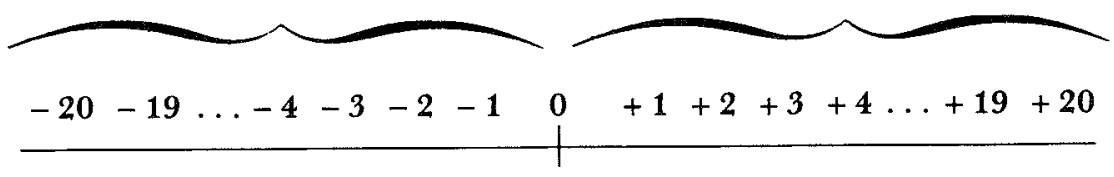

The week of the management forecast

\section{B. Methodology}

This study examines two hypotheses. One is that financial analysts react to earnings forecasts released by management. The second is that the analysts react optimally.

The first null hypothesis to be tested is that the level of variability in the mean analyst forecast is not abnormally elevated during the time period surrounding the public release of a management forecast. In order to test the hypothesis a normal (or expected) level of FA forecast volatility is established by examining a period of time removed from the date of the management forecast. Then the FA forecast volatility during the period surrounding the management forecast is tested for a significant difference from this "normal" level. Finding significant levels of abnormal volatility would be consistent with the hypothesis that analysts find management forecasts useful in preparing their EPS forecasts.

The test for a non-normal level of FA forecast volatility is an application of the traditional Fama, Fisher, Jensen and Roll (1969) event study methodology. In this case, the release of the management forecast is the event of interest, and the weekly percent changes in the consensus analyst EPS forecasts are the variables of interest (in place of security returns). In this study, the expected level of the weekly percent change in the financial analyst forecast (FAF) is established by calculating the sample mean percent change in the FAF in the weeks prior to the manager's announcement. Although this represents a fairly naive approach to forming an expectation, the results of Brown and Warner (1980) 
and (1984) demonstrate that this approach is as well specified and as powerful as more sophisticated techniques. Three alternative time periods are employed in this study to calculate the sample mean:

1. weeks -16 through -1 ;

2. weeks -18 through -3 ; and,

3. weeks -20 through -5 .

Using three estimates of the expected change in the FAF should provide some idea of the robustness of the test to a particular specification of the expectation.

An abnormal change in the consensus FAF is defined as a change in the FAF different from the change that was expected. If the expected change in the consensus FAF for firm $j$ is denoted $F_{j}$, the abnormal change for this firm in week $\mathrm{t}\left(\mathrm{AC}_{\mathrm{j}, \mathrm{t}}\right)$ is:

$$
A C_{j, t}=F_{j, t}-F_{j} \text {, }
$$

where $F_{j, t}=$ the actual percent change in firm j's consensus FAF in week t. The variable of interest in the statistical test is the cross-sectional average abnormal change,

$$
\overline{\mathrm{AC}}_{\mathrm{t}}=\left(1 / \mathrm{N}_{\mathrm{t}}\right) \sum_{\mathrm{j}=1}^{\mathrm{N}_{\mathrm{t}}} \mathrm{AC}_{\mathrm{j}, \mathrm{t}}
$$

where $N_{t}=$ the number of firms with valid FAF data in week $t$. As with any event study, we rely on the Law of Large Numbers to eliminate any systematic effect on the average abnormal change other than the event of interest. In other words, it is recognized that other (not related to the MF) data are constantly affecting the FAF. However, if the number of event dates in the study is "large enough," and if the event dates are not "too close" together in calendar time, the "other" news will cause some firms' EPS forecasts to be revised upward and some others to be revised downward. However, given the previous assumptions, no systematic effect other than that caused by the event of interest should be evident. Evidence in Brown and Warner (1980) and (1984) suggests that this methodology is well specified.

The null hypothesis tested each week is:

$$
\mathrm{H}_{\mathrm{O}}: \overline{\mathrm{AC}}_{\mathrm{t}}=0 \text {, }
$$


with an alternative hypothesis of

$$
\mathrm{H}_{\mathrm{A}}: \overline{\mathrm{AC}}_{\mathrm{t}} \neq 0 \text {. }
$$

Rejection of the null is support for the conjecture that financial analysts respond to the public release of management earnings forecasts. The statistical test of significant is done using a traditional $\mathrm{T}$-test. ${ }^{5}$

This technique also provides direct evidence whether the analyst is able to anticipate the information contained in a management forecast or only reacts to the public announcement. If the elevation in FA forecast volatility occurs after the announcement date, the analyst apparently is unable to independently produce the information contained in the management forecast and must rely on the announcement itself to provide the information. It is conceivable, however, that the analyst is able to duplicate the information contained in the management forecast from alternative sources, i.e., related news items. In that case, the data should show elevation in FA forecast variability prior to the actual date at which management publicly releases a forecast.

Examining the issue of whether analysts respond in an optimal manner to the release of management EPS forecasts is more descriptive in nature. In order to determine how analysts should react to a management forecast, the management forecast and the financial analyst forecast that exists the week the management forecast is released $\left(\mathrm{FAF}_{0}\right)$ are compared to actual earnings. Obviously this comparison requires knowledge of the actual earnings $(\mathrm{AE})$ that is not available to the analyst at the time the management forecast is released. Recall, however, that the hypothesis being examined is that analysts are able to combine the information in a MF with their own information to produce superior EPS forecasts. Whether the FAFs are superior must be judged relative to the actual earnings which eventually are revealed. The $\mathrm{MF}, \mathrm{FAF}_{0}$ and $\mathrm{AE}$ have one of three relative size relationships. 6 The analyst forecast may:

1. have a forecast error $\left(\mathrm{FAF}_{0}-\mathrm{AE}\right)$ with the same sign as the management forecast error $(\mathrm{MF}-\mathrm{AE})$, but be smaller in absolute value, i.e., be more accurate than the management forecast;

2. have a forecast error with a different sign than management; or 
3. have a forecast error with the same sign as the management forecast error, but be larger in absolute value, i.e., be less accurate than the management forecast.

Each of these situations calls for a different response by the analysts.

Consider the first case. We can envision an EPS number line, as illustrated in the upper panel of Figure 2. The financial analysts' forecast in week 0 lies between the management forecast and the actual earnings figure. What constitutes an optimal response to the MF by the analyst? Simply stated, the analyst should be able to use the information contained in the manager's announcement to reduce the analyst forecast error. That is, the analysts' forecasts in the weeks subsequent to the announcement date should move in the direction indicated by the arrows above the Figure 2 number lines. At a minimum, the analysts should not be misled by the manager's estimate. Likewise, the analysts should not view the management forecast as so informative as to overreact by moving past the actual earnings figure.

The middle panel of Figure 2 illustrates the second case. In this situation the manager's belief and the analysts' forecast initially are on opposite sides of the actual earnings figure. Intuition would suggest a movement toward the manager's estimate as a natural response to the new information. However, if the analysts are able to use the MF information optimally, they should not overreact. A rather strict definition of overreaction is adopted in this study. Specifically, if subsequent FAFs are revised sufficiently so that the forecast error sign becomes the same as the management forecast error, the financial analysts are said to have overreacted. The argument in favor of this definition is that, by moving the consensus forecast past the actual earnings, the analysts are placing too much weight on the MF when calculating their revised forecasts. If (on average) the analysts "overshoot" the actual earnings number, this is evidence of a tendency for the analysts to mimic the management estimate.

Finally, the third case is demonstrated in the bottom panel of Figure 2. In this case the management forecast lies between the analyst estimate and the actual earnings figure. Once again, intuition might suggest that analysts revise their beliefs by producing an averaging of their prior beliefs and the management forecast number. This would leave the revised analyst forecast somewhere between $\mathrm{FAF}_{0}$ and $\mathrm{MF}$ on the EPS number line. In order for the analyst to respond optimally to the information in the 
manager's forecast, however, he or she must produce a more accurate EPS estimate. This implies a movement past the MF and closer to the actual earnings. Thus, while the analyst appears to overreact to the release of the MF, ex post the "overreaction" is justified.

Conceivably, one could design a null hypothesis consistent with the statement that analysts do (or do not) optimally use the information contained in a MF. The approach taken here, however, is descriptive. In order to assess whether analysts behave optimally, the relative frequencies of "correct" and "incorrect" FAF revisions in each of the three cases outlined are tabulated.

FIGURE 2

Case $1-\mathbf{M F}<\mathbf{F A F}_{0}<\mathbf{A E}$ or $\mathbf{A E}<\mathbf{F A F}_{0}<\mathbf{M F}$

Analysts should not move toward the MF.

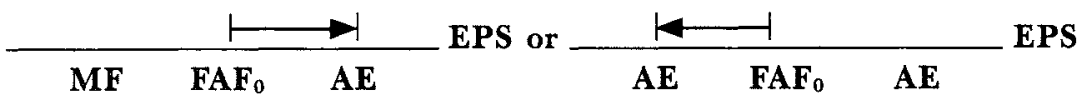

Case $2-\mathbf{M F}<\mathbf{A E}<\mathbf{F A F}_{0}$ or $\mathbf{F A F}_{0}<\mathbf{A E}<\mathbf{M F}$

Analysts should react (but not overreact) to the MF.

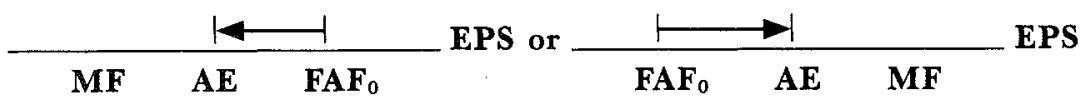

Case 3 - AE $<$ MF $<$ FAF $_{0}$ or FAF $_{0}<\mathbf{M F}<\mathbf{A E}$ Analysts should "overreact" to the MF.

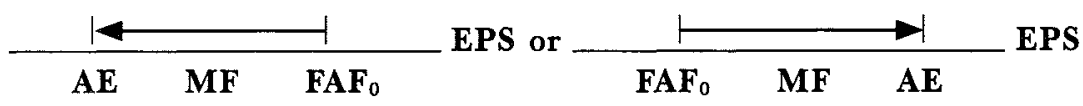




\section{ANALYST RESPONSE TO MANAGEMENT EARNINGS FORECASTS}

The first issue examined in this section is whether financial analysts react to the public release of management earnings forecasts. In order to determine this, the weekly percent change in the FAF, beginning the week the management forecast is released (week 0), is compared to the expected percent change. Initially, the expected change for each firm is derived by computing the average percent change in the sixteen weeks prior to the announcement (weeks -16 through -1 ). ${ }^{7}$ In addition to anticipating that the release of a MF might affect the FAF, a moment's reflection also provides an expectation concerning the direction of this revision. Specifically, if the level of earnings forecast by the manager is greater than the level contemporaneously predicted by the analysts, the MF constitutes "good news" and should be followed by an increase in the FAF. Analogous logic applies for "bad news." Instead of splitting the sample into good news and bad news subsamples (which would reduce sample size), the percent changes of the analyst forecast of bad news firms are multiplied by minus one $(-1)$. Thus, a positive abnormal level of revision represents a greater than expected revision in the predicted direction. The null hypothesis to be tested is that the across-firm average percent change in the FAF each week subsequent to the release of the management forecast is not different from its expected value, i.e., abnormal revision equals zero. Table 1 summarizes the findings.

The results are consistent with the claim that analysts react to the public announcement of management earnings forecasts. Significant levels of abnormal revision in the anticipated direction occur in weeks 0 through 3 . In addition, six of the first seven weeks following a MF have abnormal revision of the correct sign. Thus, the FAF revision begins at the time the management forecast is released, proceeds strongly for three weeks, and continues to drift fairly consistently in the predicted direction through the seventh week subsequent to the manager's announcement.

Another issue of interest in this study is whether the analysts are able to anticipate the news contained in the release of a MF. In order to address this issue, the level of abnormal FAF revisions in weeks preceding the release of the manager's forecast must be computed. This requires that the period of time used to compute the expected revision be modified to exclude the weeks 
immediately preceding the management announcement. Since it is also important to assess the robustness of the results to the expectation formation procedure, two alternative expectation calculation periods are examined. The first alternative estimation period includes weeks -18 through week -3 and computes abnormal FAF revision levels for weeks -2 through +20 , while the final estimation period is weeks -20 through -5 with abnormal revision computations performed for weeks -4 through +20 . Again, the null hypothesis is that no abnormal levels of FAF revision exist. Table 2 presents the findings.

TABLE 1

ABNORMAL FAF REVISION ACTIVITY FOLLOWING THE RELEASE OF MANAGEMENT EARNINGS FORECASTS

\begin{tabular}{cccc} 
Week & $\underline{\mathbf{N}}$ & Abnormal Revision & T-statistic \\
\hline 0 & 76 & .00442 & $2.296^{* *}$ \\
1 & 76 & .00599 & $1.994^{* *}$ \\
2 & 76 & .00575 & $2.677^{* * *}$ \\
3 & 76 & .00323 & $1.851^{*}$ \\
4 & 75 & .00090 & .487 \\
5 & 71 & -.00016 & -.121 \\
6 & 68 & .00651 & 1.173 \\
7 & 65 & .00083 & .535 \\
8 & 61 & -.00152 & -.673 \\
9 & 58 & -.00374 & -1.244 \\
10 & 54 & .00246 & .568 \\
11 & 50 & -.00094 & -.564 \\
12 & 45 & -.00291 & -1.301 \\
13 & 43 & -.00036 & -.112 \\
14 & 41 & -.00859 & -1.420 \\
15 & 39 & -.00843 & -930 \\
16 & 38 & .00138 & .686 \\
17 & 38 & .00586 & .844 \\
18 & 36 & -.00230 & .756 \\
19 & 34 & .00152 & .621 \\
20 & 33 & -.00053 & -.186 \\
$*$ & significant at the $90 \%$ confidence level & \\
$* *$ & significant at the $95 \%$ confidence level & \\
$* * *$ & significant at the $99 \%$ confidence level &
\end{tabular}


ABNORMAL FAF REVISION ACTIVITY AROUND THE RELEASE OF MANAGEMENT EARNINGS FORECASTS

\begin{tabular}{|c|c|c|c|c|c|c|}
\hline \multicolumn{4}{|c|}{ Estimation Period } & \multicolumn{3}{|c|}{ Estimation Period -20 to -5} \\
\hline Week & $\underline{\mathbf{N}}$ & $\begin{array}{c}\text { Abnormal } \\
\text { Revision }\end{array}$ & $\underline{T \text {-statistic }}$ & $\underline{\mathbf{N}}$ & $\begin{array}{l}\text { Abnormal } \\
\text { Revision }\end{array}$ & $\mathbf{T}$-statistic \\
\hline-4 & & & & 74 & -.00414 & -.465 \\
\hline-3 & & & & 74 & -.01225 & -1.455 \\
\hline-2 & 76 & -.00164 & -.826 & 74 & -.00914 & -1.127 \\
\hline-1 & 76 & -.00171 & -1.126 & 74 & -.00934 & -1.191 \\
\hline 0 & 76 & .00373 & $1.906^{*}$ & 74 & -.00343 & -.423 \\
\hline 1 & 76 & .00529 & $1.720^{*}$ & 74 & -.00211 & -.248 \\
\hline 2 & 76 & .00506 & $2.273^{* *}$ & 74 & -.00238 & -.289 \\
\hline 3 & 76 & .00253 & 1.391 & 74 & -.00503 & -.631 \\
\hline 4 & 75 & .00020 & .103 & 73 & -.00748 & -.918 \\
\hline 5 & 71 & -.00046 & -.358 & 69 & -.00033 & -.248 \\
\hline 6 & 68 & .00062 & 1.127 & 66 & .00723 & 1.248 \\
\hline 7 & 65 & .00058 & .373 & 63 & .00139 & .837 \\
\hline 8 & 61 & -.00183 & -.807 & 59 & -.00110 & -.493 \\
\hline 9 & 58 & -.00407 & -1.357 & 56 & -.00332 & -1.015 \\
\hline 10 & 54 & .00213 & .491 & 52 & .00315 & .679 \\
\hline 11 & 50 & -.00136 & -.816 & 48 & -.00033 & -.201 \\
\hline 12 & 45 & -.00337 & -1.506 & 43 & -.00240 & -1.065 \\
\hline 13 & 43 & -.00069 & -.210 & 41 & .00110 & .340 \\
\hline 14 & 41 & -.00895 & -1.480 & 39 & -.00789 & -1.245 \\
\hline 15 & 39 & -.00877 & -.969 & 37 & -.00801 & -.839 \\
\hline 16 & 38 & .00104 & .518 & 39 & .00222 & 1.000 \\
\hline 17 & 38 & .00552 & .795 & 36 & .00685 & .946 \\
\hline 18 & 36 & -.00263 & -.876 & 34 & -.00192 & -.586 \\
\hline 19 & 34 & .00118 & .508 & 32 & .00238 & .904 \\
\hline 20 & 33 & -.00091 & -.341 & 31 & .00002 & .008 \\
\hline
\end{tabular}

In neither case is there any evidence that analysts are able to anticipate the information contained in the forthcoming management forecasts. All weeks prior to the MF have negative abnormal FAF revision (implying a less than expected revision), although none are significantly less than zero.

Unfortunately, the significance of the FAF revision effect noted 
in Table 1 is diminished in the -18 to -3 estimation period and disappears entirely in the -20 to -5 estimation period. Thus, the results do not appear to be robust with respect to the estimation period used to compute the normal level of FAF revision.

Below, it will be argued that the results presented in Table 2 are potentially misleading due to the inclusion of "information" events that should not be expected to alter the consensus FAF. Before exploring that point, however, let us see what can be learned from an examination of Tables 1 and 2.

As noted previously, all of the FAF revisions in the weeks prior to the $\mathrm{MF}$ are less than the revisions expected. In addition, the level of abnormal revision in periods subsequent to the management's forecast diminish as the expectation estimation period is pushed further back in time. Both of these imply that the percent changes in the FAF decline in the weeks immediately prior to the release of the manager's announcement. That is, the average percent change in weeks -20 to -5 is greater than the average in weeks -18 to -3 which, in turn, exceeds that of weeks -16 to -1 . Thus, it requires a larger FAF change to be considered significantly abnormal in any given week using the expectation calculated over the -20 to -5 estimation period than the expectation calculated in the -16 to -1 period.

While this phenomenon may be consistent with several hypotheses, one of interest in this context concerns the behavior of analysts. If analysts are able to anticipate the release of a management forecast, it may be reasonable to assume that the observed revision activity would decline just prior to the anticipated date of the management announcement. This may be true if analysts defer an analysis of a firm in anticipation of an upcoming news event that would have a significant impact on that analysis. Thus, the reduction in FAF volatility prior to the MF date is consistent with analysts having the ability to predict the forthcoming news event. Analysts apparently are unable to determine the information content of the management announcement, however, since no movement of the consensus analyst forecast in the predicted direction prior to the public announcement is evident.

Let us now return to the statement made previously that the results in Table 2 may be misleading. The figures in Table 2 (as well as Table 1) reflect the inclusion of all management forecasts in the sample. Some of these MF, however, may be expected to lead to minimal changes in the consensus FAF. Specifically, if the MF is nearly equal to the current consensus FAF, the consensus forecast 
would not be expected to change a great deal. ${ }^{8}$ Despite this potential problem, the conclusions of Table 1 are reasonably strong. The weakness of the findings in Table 2 , however, indicate a need to examine whether the surprise contained in the management forecast affects the financial analyst response. In order to investigate this issue, the tests to Table 2 are rerun with the additional requirement that the management forecast differs from the contemporaneous analyst consensus forecast $\left(\mathrm{FAF}_{0}\right)$ by at least 2.5 percent. The 2.5 percent filter is admittedly arbitrary. If the analysts' uncertainty about EPS could be characterized with a normal distribution and if there was a large number of analysts forecasting the earnings of each firm, the across-analyst standard deviation of forecasts could be used to determine whether a given $\mathrm{MF}$ was significantly different from the $\mathrm{FAF}_{0}$. Unfortunately, the normal distribution assumption is somewhat suspect and some of the firms have only a few analysts following them. Therefore, a small (but arbitrary) filter is selected to test the sensitivity of the results to this issue. Table 3 contains the results of this revised analysis.

The findings of Table 3 are consistent with the hypothesis that the analysts react to the release of the management forecast but are unable to anticipate the content of the announcement. In both cases the FAF revision activity was abnormally high on a fairly consistent basis in weeks 0 through 7 with the FAF revision in weeks 0 and 2 being significantly elevated at the ninety-five percent confidence level. The revision activity in week 1 is marginally insignificant (the critical t-statistic is 1.65 for the ninety percent confidence level) for the first estimation period and marginally significant in the second estimation period. Finally, in five of the six weeks prior to the release of the MF the level of analysts forecast revision is less than expected (negative abnormal changes). Thus, with a fairly low filter for the minimal divergence of the $\mathrm{MF}$ from the $\mathrm{FAF}_{0}$, the rather clean results of Table 1 are extended to the two alternative estimation periods. ${ }^{9}$

While one might expect the results to continue to strengthen as the divergence filter is increased, this is not the case. In Table 4 the results of the same test using only those events in which the MF differs from the $\mathrm{FAF}_{0}$ by at least ten percent are reported. ${ }^{10}$

Although the week 0 and week 2 FAF revisions are significantly greater than expected, the t-statistics are consistently less than the comparable t's with the 2.5 percent filter. Also, the week 1 level of revision is insignificantly greater than normal with all three estimation periods while it was significantly elevated in two of the 
three estimation periods using the smaller filter and only marginally insignificant in the third estimation period. Finally, the pre-event reaction documented in Table 4 is different from the reaction using the zero percent or 2.5 percent filters. The pre-event results for the -18 to -3 estimation period, while still negative are considerably smaller than those with the 2.5 percent filter in effect. Using the -20 to -5 estimation period, three of the four pre-event weeks have greater than expected forecast revisions.

TABLE 3

\section{ABNORMAL FAF REVISION ACTIVITY AROUND THE RELEASE OF MANAGEMENT EARNINGS FORECASTS $\left(\mathbf{M F}-\mathrm{FAF}_{0}\right) / \mathrm{FAF}_{\mathbf{0}} \mid \geqslant .025$}

\begin{tabular}{|c|c|c|c|c|c|c|}
\hline \multicolumn{3}{|c|}{ Estimation Period } & -18 to -3 & \multicolumn{2}{|c|}{ Estimation Period } & -20 to -5 \\
\hline Week & $\underline{\mathbf{N}}$ & $\begin{array}{c}\text { Abnormal } \\
\text { Revision }\end{array}$ & $\underline{\mathbf{T} \text {-statistic }}$ & $\underline{\mathbf{N}}$ & $\begin{array}{c}\text { Abnormal } \\
\text { Revision }\end{array}$ & T-statistic \\
\hline-4 & & & & 63 & .00369 & .761 \\
\hline-3 & & & & 63 & -.00502 & -1.297 \\
\hline-2 & 63 & -.00280 & 1.277 & 63 & -.00244 & -.992 \\
\hline-1 & 63 & -.00204 & -1.120 & 63 & -.00167 & -.898 \\
\hline 0 & 63 & .00473 & $2.044^{* *}$ & 63 & .00510 & $2.219^{*}$ \\
\hline 1 & 63 & .00599 & 1.620 & 63 & .00636 & $1.700^{*}$ \\
\hline 2 & 63 & .00555 & $2.097 * *$ & 63 & .00591 & $2.120^{* *}$ \\
\hline 3 & 63 & .00259 & 1.187 & 63 & .00296 & 1.286 \\
\hline 4 & 62 & .00043 & .186 & 62 & .00080 & .364 \\
\hline 5 & 60 & -.00091 & -.607 & 60 & -.00051 & -.333 \\
\hline 6 & 57 & .00730 & 1.105 & 57 & .00838 & 1.249 \\
\hline 7 & 56 & .00050 & .276 & 56 & .00159 & .850 \\
\hline 8 & 53 & -.00274 & -1.063 & 53 & -.00159 & -.646 \\
\hline 9 & 51 & -.00485 & -1.425 & 51 & -.00365 & 1.016 \\
\hline 10 & 47 & .00164 & .328 & 47 & .00290 & .565 \\
\hline 11 & 44 & -.00168 & -.886 & 44 & -.00032 & -.180 \\
\hline 12 & 40 & -.00412 & $-1.652^{*}$ & 40 & -.00265 & -1.094 \\
\hline 13 & 38 & -.00046 & -.124 & 38 & .00114 & .327 \\
\hline 14 & 36 & -.01003 & -1.463 & 36 & -.00837 & -1.270 \\
\hline 15 & 34 & -.01022 & -.986 & 34 & -.00867 & -.834 \\
\hline 16 & 33 & .00049 & .217 & 33 & .00203 & .848 \\
\hline 17 & 33 & .00640 & .801 & 33 & .00794 & .992 \\
\hline 18 & 31 & -.00301 & -.868 & 31 & -.00173 & -.482 \\
\hline 19 & 30 & .00055 & .211 & 30 & .00209 & .747 \\
\hline 20 & 29 & -.00026 & -.093 & 29 & .00137 & .477 \\
\hline
\end{tabular}

* significant, $\alpha=.10$

** significant, $\alpha=.05$ 
TABLE 4

ABNORMAL FAF REVISION ACTIVITY AROUND THE RELEASE OF MANAGEMENT EARNINGS FORECASTS

$\left|\left(\mathbf{M F}-\mathrm{FAF}_{0}\right) / \mathrm{FAF}_{0}\right| \geqslant .010$

\begin{tabular}{|c|c|c|c|c|c|c|c|c|c|}
\hline \multirow[b]{2}{*}{ Week } & \multicolumn{3}{|c|}{ Estimation Period -16 to -1} & \multicolumn{3}{|c|}{ Estimation Period -18 to -3} & \multicolumn{3}{|c|}{ Estimation Period -20 to -5} \\
\hline & $\underline{\mathbf{N}}$ & Abnormal Revision & $\underline{T}$ & $\underline{\mathbf{N}}$ & Abnormal Revision & $\underline{\mathbf{T}}$ & $\underline{\mathbf{N}}$ & Abnormal Revision & $\underline{T}$ \\
\hline-4 & & & & & & & 43 & .00721 & 1.03 \\
\hline-3 & & & & & & & 43 & -.00320 & -1.17 \\
\hline-2 & & & & 43 & -.00052 & -.233 & 43 & .00052 & .215 \\
\hline-1 & & & & 43 & -.00082 & -.467 & 43 & .00019 & .094 \\
\hline 0 & 43 & .00645 & $2.06 * *$ & 43 & .00552 & $1.69^{*}$ & 43 & .00656 & $2.01^{*}$ \\
\hline 1 & 43 & .00561 & 1.24 & 43 & .00469 & .987 & 43 & .00573 & 1.23 \\
\hline 2 & 43 & .00697 & $1.98^{*}$ & 43 & .00605 & $1.65^{*}$ & 43 & .00709 & $1.87^{*}$ \\
\hline 3 & 43 & .00312 & 1.14 & 43 & .00219 & .742 & 43 & .00323 & .991 \\
\hline 4 & 42 & .00132 & .427 & 42 & .00038 & .114 & 42 & .00144 & .451 \\
\hline 5 & 40 & -.00195 & -1.03 & 40 & -.00216 & -1.11 & 40 & -.00102 & -.473 \\
\hline 6 & 39 & .01067 & 1.11 & 39 & .01040 & 1.08 & 39 & .01156 & 1.18 \\
\hline 7 & 38 & -.00055 & -.246 & 38 & -.00079 & -.346 & 38 & .00040 & .163 \\
\hline 8 & 35 & -.00078 & -.306 & 35 & -.00113 & -.435 & 35 & .00017 & .062 \\
\hline 9 & 33 & -.00794 & -1.64 & 33 & -.00831 & $-1.71^{*}$ & 33 & -.00693 & -1.33 \\
\hline 10 & 30 & .00464 & .633 & 30 & .00429 & .583 & 30 & .00574 & .748 \\
\hline
\end{tabular}


The combination of a stronger pre-event forecast revision and a weaker post-event reaction is consistent with several hypotheses about analyst behavior. One is that, because the ten percent filter leaves a sample of more newsworthy events than the zero or 2.5 percent filter, the analysts are better able to anticipate the content of the upcoming earnings announcement by monitoring alternative news sources. Thus, as the analysts monitor their other data sources, they are more likely to uncover related information that is significant enough to force them to revise their beliefs prior to the MF date. This implies that part of the FAF revision takes place before the MF is announced leaving less to take place in the post-event period.

The evidence presented thus far appears to indicate that analysts do indeed respond to management earnings forecasts and that analysts do not seem to be able to anticipate the information contained in these announcements. In the remainder of this section, the possibility of observing different analyst responses to various subsamples of the data is investigated. A somewhat different response has already been noted when we divide the data based on the size of the discrepancy of the MF from the current (time zero) FAF.

The two factors that were chosen to subdivide the sample are: 1 ) the year in which the MF is made; and 2) the half of the fiscal year in which the MF was made. Along the first dimension the sample was divided into those MFs occurring in 1979-80 and those in 1981-82. The first time period represents a time over which market-wide corporate earnings were relatively flat, while the latter dates represent a period over which earnings fell dramatically with some recovery at the end of 1982 . Table 5 presents the results using a zero filter and the -18 to -3 estimation period. ${ }^{11}$

The results indicate a marked difference in analyst response during the two time periods. The 1979-80 time period results indicate no significant analyst response except in week 5 . However, the sign of the abnormal revision in that, as in weeks $0,1,3$ and 4, was the reverse of that hypothesized. On the other hand, the 1981-82 findings indicate a strong and consistently significant FAF revision in the expected direction for weeks 0 through 5 . One potential explanation for this phenomenon revolves around the relative uncertainty and volatility of the two periods. The year 1981 marked the beginning of a fairly severe recession and a period of relatively high uncertainty for analysts. In this enviroment the analysts are more likely to be influenced by and hypersensitive to any data source they view as informed. ${ }^{12}$ 
TABLE 5

ABNORMAL FAF REVISION AROUND THE

RELEASE OF MANAGEMENT EARNINGS FORECAST

(Differentiated by year released.)

1979-80

$\begin{array}{rrrr}\text { Week } & & \frac{\mathbf{N}}{42} & \begin{array}{c}\text { Abnormal } \\ \text { Revision }\end{array} \\ -2 & 42 & -.00202 \\ -1 & 42 & -.00208 \\ 0 & 42 & -.00083 \\ 1 & 42 & -.00251 \\ 2 & 42 & .00232 \\ 3 & 42 & -.00057 \\ 4 & 42 & -.00303 \\ 5 & 37 & -.00373 \\ 6 & 37 & .00036 \\ 7 & 35 & -.00141 \\ 8 & 32 & -.00558 \\ 9 & 30 & -.00813 \\ 10 & 29 & .00729 \\ * & \text { significant, } \alpha=.10 \\ * * & \text { significant, } \alpha=.05 \\ * * * & \text { significant, } \alpha=.02\end{array}$

$1981-82$

\begin{tabular}{lcl}
\cline { 2 - 3 } $\mathbf{N}$ & $\begin{array}{c}\text { Abnormal } \\
\text { Revision }\end{array}$ & T-statistic \\
34 & -.00136 & -.3966 \\
34 & -.00134 & -.4685 \\
34 & .00704 & $2.4608^{*}$ \\
34 & .01537 & $2.8372^{* * *}$ \\
34 & .00878 & $3.2233^{* * *}$ \\
34 & .00630 & $1.8580^{*}$ \\
34 & .00461 & $2.0756^{* *}$ \\
34 & .00371 & $1.9262^{*}$ \\
31 & .01371 & 1.1716 \\
30 & .00311 & 1.1062 \\
29 & .00238 & 1.3489 \\
28 & .00049 & .4141 \\
25 & .00007 & .0281
\end{tabular}

Table 6 presents the results of the partitioning of the sample into announcements occurring in the first and second half of the fiscal year. Once again, the -18 to -3 estimation period is used with a zero filter. While the differential nature of results in Table 6 are not as extreme as those in Table 5, the first half of year MFs seem to elicit a reaction effect similar to the overall results. Management forecasts released late in the year are not associated with any significant analyst response in the predicted direction. One possible explanation for this differential response is that, given the extra time for analysts to gather information relevant to estimating earnings, the management forecasts released late in the year have less of a surprise associated with them. That is, the MF diverges less from the $\mathrm{FAF}_{0}$. In addition, even with an equivalent surprise, financial analysts may have a relatively high level of uncertainty about earnings early in the fiscal year, which may make them more sensitive to new data. The data support both of these conjectures, 
although the former one is only marginally supported. In order to examine these issues the absolute percent deviation of the management forecast form the contemporaneous consensus analyst estimate $\left[\left|\left(\mathrm{MF} / \mathrm{FAF}_{0}\right)-1\right|\right]$ and the coefficient of variation of the analysts forecast (the across-analyst standard deviation of forecasts divided by the consensus forecast) are calculated. The average divergence for those management forecasts issued early in the fiscal year is 10.69 percent while the average for those released in the latter half of the year averaged a 10.26 percent deviation. Calculating the average coefficient of variations produces a value of .0834 for the early forecasts and .0549 for those released later. Thus, it appears that the uncertainty effect may play a more dominant role in explaining the differential results of Table 6 .

TABLE 6

ABNORMAL FAF REVISION AROUND THE RELEASE OF A MANAGEMENT EARNINGS FORECAST (Differentiated by time of release within the fiscal year.)

\section{First half}

\begin{tabular}{|c|c|c|c|}
\hline Week & $\underline{\mathbf{N}}$ & $\begin{array}{c}\text { Abnormal } \\
\text { Revision }\end{array}$ & $\underline{T \text {-statistic }}$ \\
\hline-2 & 26 & -.00491 & -1.4721 \\
\hline-1 & 26 & -.00350 & -1.1356 \\
\hline 0 & 26 & .00202 & .7416 \\
\hline 1 & 26 & .01571 & $2.4294^{* *}$ \\
\hline 2 & 26 & .00407 & $1.9063^{*}$ \\
\hline 3 & 26 & .00150 & .5993 \\
\hline 4 & 26 & -.00142 & -.3414 \\
\hline 5 & 26 & .00288 & 1.3797 \\
\hline 6 & 26 & .00310 & 1.5165 \\
\hline 7 & 26 & .00432 & 1.2667 \\
\hline 8 & 26 & .00083 & .3228 \\
\hline 9 & 26 & .00022 & .0879 \\
\hline 10 & 26 & -.00000 & -.0021 \\
\hline
\end{tabular}

\section{Second half}

\begin{tabular}{ccc}
$\mathbf{N}$ & $\begin{array}{c}\text { Abnormal } \\
\text { Revision }\end{array}$ & T-statistic \\
\hline 50 & -.02375 & -.9974 \\
50 & -.00173 & -.9730 \\
50 & .00518 & 1.4248 \\
50 & -.00027 & -.0883 \\
50 & .00028 & .0419 \\
50 & .00195 & .7645 \\
50 & -.00009 & -.0430 \\
46 & -.00301 & $-1.7394^{*}$ \\
43 & -.00095 & -.2915 \\
43 & -.00222 & $-1.6733^{*}$ \\
36 & -.00527 & 1.5000 \\
33 & -.00874 & $-1.7870^{*}$ \\
29 & .00432 & .5465
\end{tabular}


This section has examined the question of whether financial analysts react to the public announcement of management earnings forecasts. The findings indicate that an abnormally high level of FAF revision is associated with such a news event. In addition, there is no evidence that analysts are able to anticipate the information contained in the MF. Finally, different analyst responses were documented by subdividing the sample based on the difference between the analysts' and the management's forecasts, the year in which the management forecast occurred and the half of the fiscal year in which the forecast occurred. 


\section{THE OPTIMALITY OF ANALYST RESPONSE}

Evidence in the previous section indicates that financial analysts do appear to respond to the information contained in the earnings forecast released by management. In this section the analysis is carried a step further. Specifically, the issue of whether the reaction by analysts indicates that they are able to combine the MF with prior information to produce superior earnings forecasts or whether they tend merely to mimic the MF is examined. If analysts only mimic management estimates, the Securities and Exchange Commission should be able to reduce society's resource expenditure on information production by mandating management earnings forecasts.

In order to discuss whether analysts react as they "should" upon the release of a management earnings estimate, hindsight is employed by comparing the relative magnitudes of the $\mathrm{MF}$, the $\mathrm{FAF}_{0}$ and the AE. Given the three quantities, there are six (3!) possibilities for the relative magnitudes to arrange themselves. The possible permutations are:

$$
\begin{array}{ll}
\text { 1. } & \mathrm{AE} \leqslant \mathrm{FAF} \leqslant \mathrm{MF} \\
\text { 2. } & \mathrm{MF} \leqslant \mathrm{FAF} \leqslant \mathrm{AE} \\
\text { 3. } & \mathrm{MF} \leqslant \mathrm{AE} \leqslant \mathrm{FAF} \\
\text { 4. } & \mathrm{FAF} \leqslant \mathrm{AE} \leqslant \mathrm{MF} \\
\text { 5. } & \mathrm{FAF} \leqslant \mathrm{MF} \leqslant \mathrm{AE} ; \text { and } \\
\text { 6. } & \mathrm{AE} \leqslant \mathrm{MF} \leqslant \mathrm{FAF}
\end{array}
$$

If analysts are able to use the management forecast information optimally, three correct (again with twenty/twenty hindsight) reactions emerge. The first two cases represent situations in which the analyst should at least refuse to be misled by the manager's forecast and preferably move his or her forecast away from the management number. Permutations three and four represent situations in which analysts should move toward the management forecast but should not overreact. The final two possibilities are situations in which analysts should "overreact" to the management forecast by moving past the management number to a revised forecast closer to the actual. Each of these hypotheses are investigated in the paragraphs below.

The sample events for the second set of tests include the 
seventy-six events listed in the Appendix plus two additional firms that had missing data in the twenty weeks prior to the management forecast date. ${ }^{14}$ While this missing data forced these firms to be excluded from the prior portion of the study (which required a calculation of the expected FAF revision based on this prior data), no data prior to the MF is necessary for the latter tests. Thus, the sample in this section consists of seventy-eight events. Of these seventy-eight events fourteen are classified as Case 1, twenty-four as Case 2 and forty fit the Case 3 classification. The relative frequencies of firms in each classification is consistent with previous work [see Jaggi (1980)] which finds that management EPS forecasts are more accurate than contemporaneous financial analyst estimates. It is interesting to note that for the majority of the events included in the study (seventy-one percent), the analysts and the management forecast error has the same sign. This is consistent with the hypothesis that the two groups use similar sets of data to construct their forecasts.

In Table 7 the relative frequency of correct reactions by analysts are summarized. The results are subdivided by the size of forecast discrepancy and the length of time (in weeks) post-announcement for observing the revised FAF for determining whether correct movements have been made. Forecast discrepancy filters of zero, 2.5, 5.0 and 10.0 percent are employed. (Recall that a five percent filter implies that the contemporaneous FAF differs from the MF by at least five percent.) In order to determine whether the financial analysts respond correctly, the changes in their forecasts, relative to their time zero forecast, are computed at weeks $+2,+4$ and +8 . That is, $\mathrm{FAF}_{2}, \mathrm{FAF}_{4}$ and $\mathrm{FAF}_{8}$ are compared to $\mathrm{FAF}_{0}$ and classified as either correct or incorrect revisions. A maximum of eight weeks was chosen since the results of the previous section indicated that analysts adjust their forecasts by that time. Thus, the 72.7 entry in the 4 week, $2.5 \%$ filter position in the Case 1 panel signifies that, of the firms in which the manager was less accurate than the analysts (but had the same forecast error sign) and the MF differed from $\mathrm{FAF}_{0}$ by at least $2.5 \%, 72.7 \%$ of the time the $\mathrm{FA}$ had either ignored or had moved away from the MF by the fourth week after the manager's announcement.

Consider the first panel of Table 7. In these fourteen cases both the manager and the analyst begin (at time zero) with forecast errors of the same sign, i.e., they both overestimate or both underestimate earnings. However, the analyst forecast is more accurate. An optimal interpretation of this $\mathrm{MF}$ would require analysts to view the firm-specific news in a manner that would lead 
the analysts to ignore or move away from the MF. This implies that the analyst forecast should not be made less accurate by the release of the MF.

\section{TABLE 7}

\section{PERCENT OF EARNINGS ANNOUNCEMENTS TO WHICH FINANCIAL ANALYSTS RESPOND "CORRECTLY"}

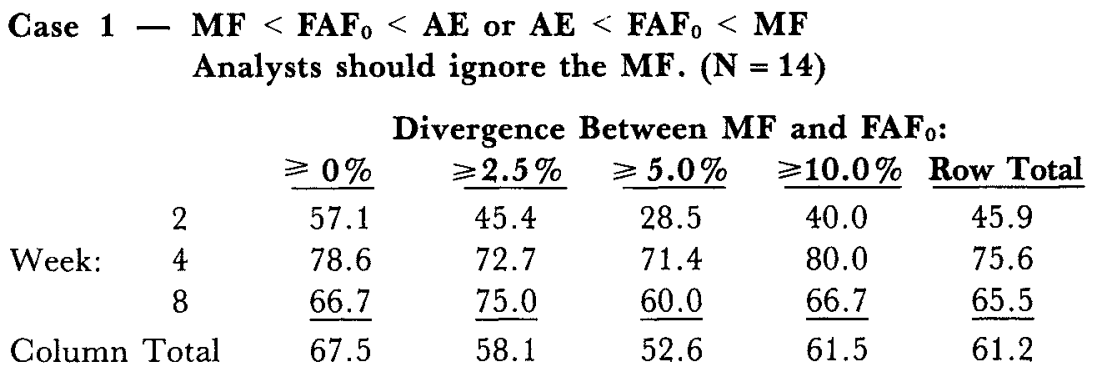

Case $2-\mathbf{F A F}_{0}<\mathbf{A E}<\mathbf{M F}$ or $\mathbf{M F}<\mathbf{A E}<\mathbf{F A F}_{0}$ Analysts should react, (but not overreact) to the MF. $(\mathrm{N}=24)$

Divergence Between $\mathrm{MF}$ and $\mathrm{FAF}_{0}$ :

\begin{tabular}{|c|c|c|c|c|c|c|}
\hline & & $\geqslant 0 \%$ & $\geqq 2.5 \%$ & $\geqq 5.0 \%$ & $\geqq 10.0 \%$ & Row Total \\
\hline & 2 & 40.0 & 38.9 & 33.3 & 36.4 & 37.9 \\
\hline 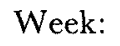 & 4 & 45.8 & 47.1 & 50.0 & 50.0 & 47.7 \\
\hline & 8 & 47.1 & 46.2 & 44.4 & 50.0 & 46.8 \\
\hline & al & 43.8 & 43.8 & 42.4 & 45.2 & 43.8 \\
\hline
\end{tabular}

Case $3-\mathbf{F A F}_{0}<\mathrm{MF}<\mathrm{AE}$ or $\mathbf{A E}<\mathrm{MF}<\mathrm{FAF}_{0}$ Analysts should overreact to the MF. $(N=40)$

Divergence Between MF and $\mathrm{FAF}_{0}$ :

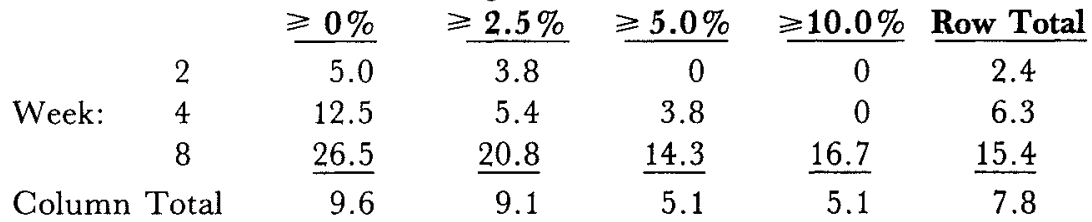


Overall, the analysts react correctly (by either not altering their week 0 forecast or moving away from the MF number) 61.2 percent of the time. Examining the column totals it appears, generally speaking, that it is more difficult for the analysts to ignore the management information the more the $\mathrm{MF}$ differs from $\mathrm{FAF}_{0}$. Each of the forecast discrepancy filters exhibit greater relative frequencies of correct revisions after the fourth and eighth weeks than after the second week. However, in three of the four columns the four-week frequencies exceed the eight-week percentages. The first result is intuitive. More time allows the analyst to gather additional data that reinforces the correct initial revisions. The latter result implies that analysts either reverse their initial direction of revision or are no longer able to ignore the manager.

The subsample summarized in the second panel of Table 7 are those cases in which the initial forecast errors of the analysts and the manager are of opposite sign. In these twenty-four cases the scenario for a correct FAF revision involves the analysts' forecasts moving toward the MF but not moving so much as to alter the sign of the $\mathrm{FAF}_{0}$ forecast error. This is true since moving past the $\mathrm{AE}$ toward the MF implies the analyst is placing "too much" emphasis on the MF. In other words, the analysts should react, but not overreact, to the MF.

The overall results indicate that about forty-four percent of the time the analysts correctly respond to this fairly strict optimality standard. These results are relatively insensitive to the divergence between the analyst and management week 0 forecast. The row totals indicate an improvement in the relative frequency of correct revisions between the second and fourth week but little change from week 4 to week 8 .

Finally, the third panel in Table 7 considers the situations in which the $\mathrm{FAF}_{0}$ and $\mathrm{MF}$ have the same sign of the forecast error but the $\mathrm{MF}$ is more accurate. In this situation an optimal response by the FA required that he or she "overreact" to the MF, i.e., that the consensus FAF be revised so that it is more accurate than the manager's forecast. This and Case 1 are the most interesting cases in many ways since, in each situation, analyst behavior that tends to mimic management beliefs is more readily apparent.

A cursory examination of Table 7 reveals that analysts' performance in these forty cases to be considerably weaker than the previous two situations. While the FAF was revised toward the announced MF number in almost all cases, in less than 8 percent of the observations are the analysts willing to "overreact." A rather surprising result is that the analysts are less willing to move past the 
$M F$ in those situations in which the $\mathrm{MF}$ differs from the $\mathrm{FAF}_{0}$ by larger margins. Furthermore, on a relative basis, the sensitivity of the results to the time period is greater than the previously examined two cases. (With the zero filter the movements from two to four weeks and from four to seven weeks both double the relative frequency of a correct movement.)

In this section the issue of whether analysts optimally respond to the release of a management forecast in a descriptive fashion has been examined. The findings indicate that analysts are fairly successful in identifying those cases in which they should ignore or move away from the management forecast. In this case the analysts correctly react over sixty-one percent of the time. Results from the middle panel of Table 7 indicate that in those cases in which the analyst and management initially have forecast errors of opposite sign (i.e., one overestimates and one underestimates) analysts refrain from overreacting almost one-half of the time. The third case examined, however, demonstrates that analysts are unwilling to overreact to the MF, even in those cases in which it is (with hindsight) reasonable. Thus, the evidence on whether analysts tend to excessively mimic management is somewhat mixed.

It is difficult to identify an explanation of why analysts respond correctly to the MF relatively frequently in Cases 1 and 2 and so infrequently in the third case. One model of analyst behavior is that they tend to "split the difference" between the MF and the $\mathrm{FAF}_{0}$. The results of Cases 2 and 3 are consistent with this hypothesis. Unfortunately, this proposition does not explain the Case 1 results. Other underlying characteristics of the forecasts might help explain why analysts react as they do in the different situations. Three variables that appear to be important are the uncertainty of the analysts about their forecasts, the number of analysts following a given firm at the time of the MF and divergence of the MF from the $\mathrm{FAF}_{0}$ (i.e., the surprise).

One measure of analyst uncertainty is the coefficient variation (CV) of the individual analysts' forecasts. The CV is defined as the standard deviation of the analysts' forecasts of a given firms' EPS in week 0 divided by the consensus (mean) forecast. As analysts become less certain of the EPS they tend to disagree with each other, increasing the across-analyst variability of their forecasts and the CV. Given the results of Table 7 one would expect a low CV for Case 1 firms since the analysts appear to be relatively sure of themselves in responding to the $\mathrm{MF}$, and a high $\mathrm{CV}$ in Case 3 since the analysts underreact in this situation. In fact, however, the opposite is true. The average CV in Case 1 is .0828 versus a Case 3 
average of .0607 . Thus, it does not appear that the differential relative frequencies of a correct response noted in Table 7 can be explained by analyst uncertainty.

The number of analysts providing EPS forecasts for a firm at a given point in time may act as a proxy for the following a firm's stock enjoys. A large number of analysts indicates a firm that is more closely followed than a firm that has only a few analysts following it. A closely followed firm, in turn, is one for which a great deal of information exists and additional information in the form of a MF is less valuable (marginally speaking) than in less closely followed firms. In Case 1 the analyst is expected to ignore the management forecast. This implies that the information contained in the management forecast is relatively insignificant to the entire information set, which is consistent with the situation of a closely followed firm. In Case 2 the analyst is expected to react to the MF announcement in a controlled fashion and in Case 3 the analyst is expected to overreact. The latter two cases are consistent with an increasing importance of the MF. Therefore, if $N_{j}$ is the average number of analysts following a firm in case $j(j=1,2,3)$, one would expect $\mathrm{N}_{1} \geqslant \mathrm{~N}_{2} \geqslant \mathrm{~N}_{3}$. However, for the sample used in this study $\mathrm{N}_{1}=7.93, \mathrm{~N}_{2}=6.71$ and $\mathrm{N}_{3}=7.03$. Thus, while Case 1 does have the greatest number of analysts, the number of analysts in Cases 2 and 3 are reversed from what was expected.

The third possible explanation for the differential success of analysts in optimally responding to management forecasts is a difference in the surprise contained (measured by the difference between the $\mathrm{MF}$ and $\mathrm{FAF}_{0}$ ) in the manager's announcement. Evidence that the surprise factor tended to be lower in the first and third case is consistent with the ability of analysts to ignore management when they should (Case 1) and analysts inability to overreact (Case 3). In Case 2 the results indicated that a large majority of the analysts responses were in the correct direction; however, a significant proportion of the time analysts overreact to the information. A high surprise factor might explain this phenomenon. This is exactly what the data indicate. Cases 1 and 3 have an average deviation of the $\mathrm{MF}$ and the $\mathrm{FAF}_{0}$ of about nine percent while the Case 2 average is greater than 13.5 percent. Thus, as might be expected when the analysts and the management forecasts differ in forecast error sign, the surprise content of the MF is greater. 


\section{SUMMARY}

The purpose of this study was to examine the response of financial analysts' EPS forecasts to the release of a management earnings estimate. Of particular interest were the issues of (1) whether analysts reacted, (2) when (relative to the date of the MF) they reacted, and (3) whether they reacted "correctly." The findings indicate that analysts indeed did react to the public announcement of a MF but were unable to anticipate the content of such announcements. Overall, analysts failed to respond correctly to nearly two-thirds of the MFs. Analysts did demonstrate, however, some ability to ignore MFs when the management figure was less accurate than their own.

As with any research effort, several caveats are in order. One is that we have used consensus financial analyst forecasts instead of individual analysts' estimates. Due to a diversification effect, the consensus forecast is generally more accurate, on average, than any individual's forecast. ${ }^{15}$ Thus, the analyst accuracy may be overstated in some sense. However, this practice is consistent with previous research and its effect may be somewhat offset by the fact that all management forecasts are voluntary.

Another possible difficulty of interpreting the results is the existence of lapses in time between when the management and analyst forecasts are computed and when the forecasts are made public. This factor should present only a minor problem. The dates of the analyst forecasts are the dates on which the earnings forecasts are announced to the brokerage firm's sales force. Public dissemination begins immediately thereafter. In this case the analyst conceivably could have actually revised the estimate during the preceding day or two. Aggregation of this date to weekly observations should minimize the problem of timing misclassification. Likewise, there is little reason to believe management would delay releasing a revised forecast for any significant period of time. Overall, therefore, the dates recorded for both the management and analyst forecasts used in this study should accurately represent the point in time when the respective forecasts were produced.

Finally, there may be some concern about whether firms that voluntarily issue management forecasts are representative of all firms. Research by Imhoff (1978), Hagerman and Ruland (1979) and Penman (1980) address this issue. Firms releasing management 
forecasts, on average, are smaller in size, have greater systematic risk, have lower variability in earnings, and have common stock that has experienced greater price appreciation than control portfolios of similar firms that do not release management forecasts. In addition, analysts forecasting the earnings of firms without management EPS forecasts available tend to be less accurate than analysts that have management forecasts available. While it is not obvious that any of these factors would induce a systematic bias in to the results of this study, it is important to recognize that firms releasing management forecasts are apparently different from those that do not along several dimensions.

This paper provides some insight in to the belief revision process of financial analysts by identifying one event that analysts appear to find interesting and analyzing the analysts' response to that event. As the first (to the author's knowledge) research effort aimed at examining the factors underlying revisions in analyst forecasts, several issues are left to future research. Perhaps the most obvious need is to identify other news events that affect analysts' EPS forecasts and investigate the effect these events have on the analysts' beliefs. A number of possible events such as real investment decisions, decisions to change dividends and changes in the competitive enviroment, as well as many others, offer the potential for a significant impact on EPS.

A second avenue of investigation that would be interesting to pursue, if the data were to become available, is to compare the reactions of individual analysts to news events. Using consensus data this study finds that, on average, analysts do not do a very good job of using MF information to "correctly" revise their earnings forecasts. It may be that there exists a minority of analysts with superior abilities whose effect on the consensus FAF is being swamped by a mediocre majority. Unfortunately, the publicly available data sources provide only consensus forecasts. The investigation of whether superior analysts exist must wait for a more detailed data base.

Another refinement to the current study would be to look beyond the effect of a news event on the mean forecast. Both the Zacks and the Lynch, Jones and Ryan data bases provide a measure of the dispersion of FAF, typically the standard deviation. One might expect that news events have an effect on the standard deviation as well as the mean FAF. This implies that additional research could be conducted examining the effect of various news events on the standard deviation of FAF in isolation as well as investigating for joint movements in both variables. 
Finally, one might be able to expand the data base of management forecasts to include additional firms with multiple forecasts either within a year or over several years. This would allow an analysis aimed at whether analysts respond differently to different management forecasts prepared by the same management. It may be that management is able to establish a "track record" that affects the reaction of analysts to a particular MF. 


\section{APPENDIX \\ (Firm Name and MF Date)}

Avemco Corp - AVE (10/24/79)

Automatic Data Processing - AUD (8/24/81)

Allen Group Inc. - ALN (3/13/80, 6/26/81)

ARKLA, Inc. - ALG (5/22/80)

Arizona Public Service - AZP (11/5/80, 2/11/81)

Bangor Punta Corp - BNK (5/22/80)

Baldor Electric Co. - BEZ (3/18/80)

Baxter Travenol Labs - BAX (7/21/80)

Best Products - BES (2/6/80)

Browning Ferris, Ind. - BFI (1/29/81)

Binney and Smith, Inc. - BYS (11/20/81)

CBI Ind. - CBH (10/7/82)

Chyron Corp. - CHYC (12/11/81)

Coleman Co. - CLN (10/25/79, 7/16/82)

Crown Zellerback - ZB (10/16/79)

Community Psychiatric Centers - CMY (9/26/79, 5/22/80, 7/13/81)

Circle K Corp. - CKP $(11 / 20 / 79)$

CPC Internat'1 - CPC (7/26/79)

Dexter Corp. - DEX (12/27/79)

Eastern Gas \& Fuel - EFU (10/18/79)

Eckert Corp. - ECK (5/10/82)

El Paso Co. - ELG $(2 / 26 / 81)$

Fuqua Ind. - FQA (11/17/82)

Federal Express Corp. - FDX (3/27/80)

First Mississippi Corp. - FRM (5/29/80)

Goulds Pumps, Inc. - GULD (9/12/79)

General Cinema Corp. - GCN (7/14/80, 9/8/81)

Global Marine Inc. - GLM (7/23/81)

Harcourt Brace and Jovan., Inc. - HBJ (8/14/79)

Hoover Universal, Inc. - HVU (1/24/80)

Hercules, Inc. - HPC (2/13/81)

Heinz Co. - HNZ (1/24/80)

IMS Internat' l - IMSI (3/22/82)

Internat' 1 Mineral \& Chemicals Corp. - IGL (8/31/79, 2/28/80, $10 / 15 / 80,10 / 21 / 81)$

Jostens Inc. - JOS (1/16/80)

Kaiser Alumnium and Chemical Co. - KLU (10/14/80)

Knight-Ridder Co. - KRN (11/12/81) 
K-Mart Corp. - KM (9/20/79)

Limited Corp. - LTD (11/30/82)

Leggett and Platt - LEG (9/24/79)

MASCO Corp. - MAS (10/28/80)

MAPCO - MDA (10/6/81)

Manufacturers Hanover Corp. - MHC (10/27/80)

Nalco Chemical Co. - NLC (6/24/82)

NL Industries - NL (11/28/79)

Nucor Corp. - NUE $(8 / 28 / 79,11 / 17 / 82)$

O'Mark Ind. - OMK (4/8/81)

ONEOK Inc. - OKE (6/17/82)

Orange and Rockland Utilities - ORU (10/7/81)

Portland General Electric - PGN (5/14/80)

Raytheon - RTN (10/23/81)

Royal Crown Cola - RCC (11/6/80)

Reading and Bates - RB (2/18/82)

Scott and Fetzer - SFZ (3/25/80)

Stauffer Chemical Co. - STF (1/28/80, 1/26/81)

Sundstrand Corp. - SNS (4/15/82, 9/28/82)

Scotty's Inc. - SHB $(5 / 7 / 80)$

Standard Brands Paints - SBP (1/25/80)

U.S. Gypsum - USG (6/9/80)

U.S. Leasing - USL (10/1/81)

Vulcan Materials Co. - VMC (6/24/82)

Whittaker Corp. - WKR (9/11/79, 3/22/82)

Wickes Co. - QWIX (10/20/80) 


\section{FOOTNOTES}

1. Ample empirical evidence indicates that financial analyst earnings forecasts represents a reasonable proxy for the "market's" expectations. See for example, studies by Malkiel and Cragg (1970), Malkiel (1970) and Fried and Givoly (1982).

2. The time period of twenty weeks is necessitated by the statistical tests used to examine the hypotheses.

3. It might be instructive to discuss briefly examples of management earnings forecasts that did not meet the data requirements.

(1) By far the most frequent reason management earnings forecasts were not usable was because an EPS forecast was open-ended. For example, a forecast that read "at least" $\$ 3.00$ per share is not usable because it cannot always be unambiguously compared to the FA forecast. Other examples of open-ended wording are: greater than, record profits (losses), better than, etc.

(2) The forecast was of earnings rather than EPS.

(3) Many EPS forecasts are issued fairly close to year end. This study omitted EPS forecasts that were made within one month of year end.

(4) Many articles were retrieved for dates after year end but before audited financials were available. Any forecast made after year end was excluded from the sample.

4. The exception to this collection procedure was when management earnings forecasts occurred less than twenty weeks prior to the end of the fiscal year. In this case analysts' forecasts were included only for the length of time available in the current fiscal year.

5. The actual cross-sectional T-statistic is computed as, 


$$
\mathrm{T}_{\mathrm{t}}=\overline{\mathrm{AC}}_{\mathrm{t}} \cdot \mathrm{N}_{\mathrm{t}}(1 / 2) /\left\{\left[1 /\left(\mathrm{N}_{\mathrm{t}}-1\right)\right] \sum_{\mathrm{j}=1}^{\mathrm{N}_{\mathrm{t}}}\left(\mathrm{AC}_{\mathrm{j}, \mathrm{t}^{-}} \overline{\mathrm{AC}}_{\mathrm{t}}\right)^{2}\right\}^{(1 / 2)}
$$

6. The financial analyst forecast may change from week to week and, therefore, has a subscript denoting the week of the forecast. The management forecast, by definition, occurs in week 0 so the subscript is suppressed. Likewise, there is one actual earnings figure for each MF making the subscript unnecessary.

7. While there is nothing magical about a sixteen-week period, the idea is to select a period of time to get a reasonable estimate of the mean change, but not so long as to include nonrepresentative date. Experiments with time periods slightly longer and shorter than sixteen weeks produced similar results.

8. This does not imply that the management forecast is uninformative. It may be very valuable in confirming analysts' current beliefs. As a confirming piece of news, however, one would anticipate an effect on the across-analyst variability of forecasts rather than on the mean (consensus) forecast.

9. When the same 2.5 percent filter is applied to the estimation period beginning in week -16 , the conclusions do not change from those in Table 1.

10. The significance levels of the results using a 5 percent filter test are between those reported in Table 3 and those in Table 4.

11. For both of these tests the choice of the particular estimation period and forecast divergence filter is somewhat arbitrary. The zero filter was chosen in order to use all of the available data. In order to detect any anticipatory FAF movement one of the estimation periods that compute abnormal revisions in weeks prior to the management forecast must be used.

12. An alternative explanation is that the earnings forecasts in 1981-82 are more divergent from the 
associated FAF. Examining the number of firms included in the ten percent filter subsample negates this argument. Of the forty-two firms in the 1979-80 sample sixty percent are still in the sample with the ten percent filter in effect, while only forty-five percent are included in the ten percent filter for 1981-82.

14. The additional firms and the dates of the release of the management forecasts are Avemco (10/24/79) and Mission Insurance Group (5/23/79).

15. Employing multiple forecasts to represent a more appropriate estimate is well documented in the literature (Beaver [1982]). Also, recent Wall Street Fournal articles have noted that consensus forecasts consistently outperform individuals (April 6, 1983: 48; November 3, 1981:31). 


\section{REFERENCES}

Beaver, W. H., Financial Reporting: An Accounting Revolution

(Englewood Cliffs, N. J.: Prentice Hall, 1981), 160-163.

S. Brown and J. Warner, "Measuring Security Price Performance," Journal of Financial Economics, September 1980, 205-258.

S. Brown and J. Warner, "Using Daily Stock Returns: The Case of Event Studies," forthcoming Fournal of Financial Economics, 1984 .

E. Elton, M. Gruber and B. M. Gultekin, "Expectations and Share Prices," Management Science, Sep tember 1981, 975-987.

E. Fama, L. Fisher, M. Jensen and R. Roll, "The Adjustment of Stock Prices to New Information," International Economic Review, February 1969, 1-21.

D. Fried and D. Givoly, "Financial Analysts Forecasts of Earnings:

A Better Surrogate for Earnings Expectations," Fournal of Accounting and Economics, October 1982, 85-107.

D. Givoly and J. Lakonishok, "The Information Content of Financial Analysts' Forecasts of Earnings," Fournal of Accounting and Economics, Winter 1979, 165-185.

D. Givoly and J. Lakonishok, "Financial A nalysts' Forecast of Earnings: The Value to Investors," Fournal of Banking and Finance, September 1980, 221-233.

D. Givoly and J. Lakonishok, "Earnings Expectation and

Properties of Earnings Forecasts - A Review and Analysis of the Research," Working paper 778/83, April 1983.

N. Gonedes, N. Dopuch and S. Penman, "Disclosure Rules, Information Production and Capital Market Equilibrium: The Case of Forecast Disclosure Rules," Fournal of Accounting Research, Spring 1976, 89-137. 
R. Hagerman and W. Ruland, "The Accuracy of Management Forecasts and Forecasts of Simple Alternative Models," Fournal of Economics and Business, Spring 1979, 172-179.

E. Imhoff, "The Representativeness of Management Earnings Forecasts," The Accounting Review, October 1978, 836-850.

Jaggi, Bikki, "Further Evidence on the Accuracy of Management Forecasts Vis-a-Vis Analysts' Forecasts," The Accounting Review January 1980, 96-101.

B. Malkiel, "The Valuation of Public Utility Equities," Bell Fournal of Economics, Spring 1970, 143-160.

B. Malkiel and J. Cragg, "Expectations and the Structure of Share Prices” American Economic Review, September 1970, 601-617.

V. Neiderhoffer and P. Regan, "Earnings Changes, A nalysts' Forecasts and Stock Prices," Financial Analysts fournal, May-June 1972, 65-71.

S. Penman, "An Empirical Investigation of the Voluntary

Disclosure of Corporate Earnings Forecasts," Fournal of Accounting Research, Spring 1980, 132-160.

L. Zacks, "EPS Forecasts - Accuracy is not Enough," Financial Analysts Journal, March-A pril 1979. 